\title{
Ji-Jun Zou, Xiangwen Zhang and Lun Pan (Eds): High-Energy-High Density Fuels for Advanced Propulsion: Design and Synthesis
}

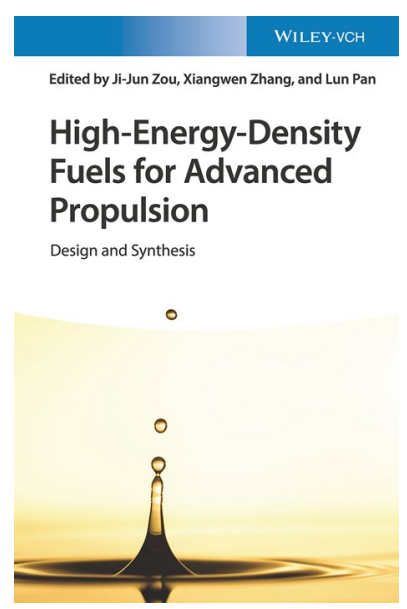

Wiley-VCH 2021

ISBN 978-3-527-34669-1

Pp xvII + 480 Price $\$ 185.00$

Some 1200 years ago, the Chinese discovered how to make gunpowder and they used it to fuel rockets; we still use gunpowder to fuel decorative rockets today. However, modern space rockets such as the Apollo rockets use fuels such as liquid oxygen and hydrogen-high energy but requiring a low temperature and low density-both undesirable. The days are long since past when the USA and the USSR had a monopoly of sending rockets into space and now many countries do so. The Chinese sent a rocket off to Mars a few months ago and so this book is appropriate.

After a short introduction one of the editors it is followed by eight substantial chapters by a total of 19 authors.
Chapter 2 gives a comprehensive account of the history and background of aerospace fuels. Chapter 3 is on high-density polyalkane fuels which contain a substantial organic chemistry content which is a feature of all the chapters. Chapter 4 is on high-density diamondoid fuels: I have to admit that, although possessing a degree in organic chemistry, most of this chapter was new to me as was much of the other chapters. Chapter 5 concerns high-energy strained quadricyclane fuels and Chapter 6 is on the increasingly important topic of high-density fuels from biomass. Chapter 7 is about nanofluid fuels and Chapter 8 returns to green fuels. The final chapter is on combustion properties of fuels and methods to improve them. The book concludes with a 5-page index.

Many countries, including the UK send up satellites for communication and navigation purposes and because of this I am able to phone countries halfway across the world as easily as I can by landline to a neighbor a mile away. But to send up a satellite requires a rocket and a rocket requires fuel which is where this book comes in. This book is a comprehensive survey of the field except in one respect-there is no information on relative costs; perhaps a future edition will include this.

This is an excellent book on a contemporary topic which is required reading for all those wishing to keep up with the latest developments.

E. R. Adlard

Publisher's Note Springer Nature remains neutral with regard to jurisdictional claims in published maps and institutional affiliations. 